\title{
"I AM MAD ABOUT SPAIN»: LA BÚSQUEDA \\ DE LA IDENTIDAD MODERNISTA A TRAVÉS DEL \\ VIAJE QUIJOTESCO EN ROSINANTE TO THE ROAD $A G A I N$ DE JOHN DOS PASSOS
}

\author{
Eulalia Piñero Gil \\ Universidad Autónoma, Madrid
}

\section{RESUMEN}

En este artículo se analiza la influencia intertextual de Don Quijote de La Mancha de Miguel de Cervantes en el libro de viajes Rosinante to the Road Again (1922) del escritor John Dos Passos para construir una épica modernista. El autor norteamericano encontró en España su propia utopía, una Arcadia que representaba la huida del monetarismo, la industrialización y el voraz capitalismo de su país. En su viaje iniciático, Dos Passos reconoce que todavía quedaban individuos españoles que encarnaban la dualidad de la mítica pareja de don Quijote y Sancho Panza y que, además, representaban la existencia de lo que él denominaba como «el gesto español». Asimismo, en Rosinante, el escritor pone a Madrid y La Mancha en el mapa de la modernidad en el contexto de otras metrópolis vanguardistas como Londres y París. El idealismo de Dos Passos transformó la Península Ibérica en el paradigma de una civilización idílica y edénica, en contraposición a las profundas contradicciones de la sociedad norteamericana, con las que el escritor era muy crítico.

Palabras clave: John Dos Passos, Rosinante to the Road Again, Miguel de Cervantes, Don Quijote de La Mancha, literatura de viajes, modernismo norteamericano, utopía.

\author{
"I AM MAD ABOUT SPAIN": THE QUEST \\ FOR A MODERNIST IDENTITY THROUGH THE QUIXOTIC JOURNEY \\ IN JOHN DOS PASSOS'S ROSINANTE TO THE ROAD AGAIN
}

\section{Abstract}

This essay analyzes the intertextual influence of Cervantes's Don Quixote of La Mancha in John Dos Passos's Rosinante to the Road Again (1922) to construct a modernist epic. The American writer found in Spain his own modernist utopia, an Arcadia that was opposed to American capitalism and monetarism. Dos Passos's journey in search of identity was based on a quest for the values that embodied by the mythical couple Don Quixote and Sancho Panza, who for the American writer became the symbol of the "Spanish gesture». Furthermore, Dos Passos was able to put Madrid and La Mancha on the map of the global scope of Modernism like other European cities such as London and Paris, in his search for the modern cosmopolitan subject. Finally, Dos Passos's idealism transformed Spanish society into an Edenic civilization and at the same time questioned the excesses of materialism and industrialism in American society.

Keywords: John Dos Passos, Rosinante to the Road Again, Miguel de Cervantes, Don Quixote of La Mancha, travel literature, American modernism, utopia.

DOI: http://doi.org/10.25145/j.refiull.2019.38.012

Revista de Filología, 38; enero 2019, pp. 185-197; ISSN: e-2530-8548 
The Spaniard, like his own Don Quixote, mounted the warhorse of his idealism and set out to free the oppressed, alone.

(Rosinante to the Road Again, 45)

\section{EL VIAJE QUIJOTESCO DE DESCUBRIMIENTO}

En octubre de 1916 el escritor norteamericano modernista de origen portugués John Dos Passos (1896-1970) se graduó cum laude en Harvard University, donde estudió lengua y literatura europeas. Su influyente padre, el abogado John Randolph Dos Passos, le propuso estudiar arquitectura en Madrid, a pesar de que el joven estaba volcado en los estudios literarios e históricos. Así pues, Dos Passos, que a la sazón tenía veinte años, inició su periplo vital en la capital española para comenzar sus estudios de arquitectura, pero también quería aprovechar el viaje para mejorar su español. Por aquel entonces, este escritor ya encarnaba el mito quijotesco del devorador de libros y era un erudito apasionado de la literatura española. En realidad, y tal y como confesó en sus anotaciones biográficas, las influencias literarias más notables en su quehacer como escritor fueron Vanity Fair de William Thackeray y Don Quijote de La Mancha de Miguel de Cervantes. Esta primera incursión en la Península Ibérica supuso la constatación de sus expectativas sobre la cultura española y fue el inicio de una larga serie de viajes a nuestro país durante toda su vida. De hecho, su fascinación e interés por España se ven reflejados en la correspondencia que mantuvo con amigos muy cercanos desde la capital madrileńa, en la que mostraba un entusiasmo inusitado por la idiosincrasia cultural, el arte, la literatura, los paisajes, las gentes y las costumbres españolas. En efecto, su apasionada inmersión en la Península Ibérica se puede constatar tanto en su obra Rosinante to the Road Again (1922), objeto de estudio en este artículo, y en su poemario A Pushcart at the Curb (1922), en el que dedica la gran mayoría de los poemas a retratar verbalmente escenas pintorescas de sus viajes por Madrid, Castilla, La Mancha y otras zonas españolas para confirmar, en múltiples ocasiones, que efectivamente se encontraba en la tierra de su admirado don Quijote (Piñero Gil 2018).

Pero además de su pasión por los viajes, la literatura y la historia, Dos Passos era muy inquieto políticamente, quizás como reacción freudiana a su padre, que, además de ser un reputado abogado vinculado con las grandes empresas de construcción, tenía un perfil ideológico muy conservador. De hecho, el joven se comprometió abiertamente con ideologías radicales vinculadas al anarquismo, en buena medida, como resultado de su profunda amistad con la anarquista lituanajudía Emma Goldman y la poderosa influencia que esta ejerció sobre el escritor. Sin embargo, hay que destacar que, a pesar de declinarse por las ideas anarquistas y comunistas, Dos Passos era un joven pacifista y profundamente idealista. El primer viaje iniciático del escritor a nuestro país estaba repleto de sueńos e ideales, pero a la vez también era una etapa en la que el escritor atravesaba una profunda crisis con respecto a los cambios vertiginosos que estaban experimentando Estados Unidos y los países europeos: la rápida industrialización, el materialismo moneta- 
rista de la sociedad norteamericana, la mecanización de la cultura y, por último, la crisis de valores generada a ambos lados del Atlántico por los efectos devastadores de la Primera Guerra Mundial. Para Dos Passos el conflicto bélico mundial era el resultado directo de los males de la civilización industrial y materialista en los países occidentales. En todo caso, las atrocidades que pudo constatar con sus propios ojos, cuando fue conductor de ambulancias en Francia, confirmaron esta idea y se propuso escribir novelas que retrataran la crudeza, el horror, el desgarro emocional y las consecuencias de las guerras en el ser humano, como es el caso de su novela antibelicista Three Soldiers (1921).

La gran crisis emocional y el escepticismo que le ocasionó su experiencia directa en el escenario bélico francés se pueden percibir en los poemas que dedicó a la destrucción moral y física de esta guerra en el poemario anteriormente mencionado. En este contexto desolador, el impacto intelectual y emocional que le causó nuestro país fue extraordinario en todo lo referente al mundo literario, social, político, artístico e, incluso, gastronómico. De hecho, se encontró con una nación europea que no había participado en la Primera Guerra Mundial y que gozaba de cierta prosperidad económica debido a su neutralidad en el conflicto bélico y a su papel como suministradora de material textil y de origen siderúrgico para los soldados. En pocos meses España se convirtió para el escritor en el epítome de la Arcadia modernista, de la utopía histórica que los escritores de la vanguardia norteamericana buscaban como inspiración literaria. El viaje espiritual de Dos Passos a España no era turístico y no tenía el carácter folklórico y un tanto superficial que se aprecia en las percepciones de otros viajeros-escritores norteamericanos famosos como Ernest Hemingway. Por el contrario, el viaje de Dos Passos estaba basado en la profunda curiosidad interdisciplinar que sentía el escritor por nuestro país. Para ello, no dudó en sumergirse en el estudio profundo de nuestra lengua y se matriculó en los cursos de español con el insigne fonólogo Tomás Navarro Tomás en el Centro de Estudios Históricos y en cursos avanzados de literatura española, además de solicitar una vacante en la Residencia de Estudiantes porque tenía especial interés en residir en esta prestigiosa institución madrileña de creación e intercambio científico y artístico de la Europa de entreguerras (Ludington 1998: 96). Desafortunadamente no consiguió alojarse en esta institución cultural porque tanto Dos Passos como Luis Cernuda no fueron admitidos en esa ocasión (Sáenz de la Calzada 2011: 194). Los cursos literarios en los que se matriculó se centraron en el estudio de la obra de los escritores de la Generación del 98 y leyó con pasión a Calderón, Lope, Baroja, Pérez Galdós, Manrique y Blasco Ibánez, entre otros muchos.

Pero, sin duda, el escritor español que se convirtió en la fuente de inspiración más significativa para Dos Passos fue Miguel de Cervantes y «the great epic Don Quixote of La Mancha» (Dos Passos 2011: 27), que es fuente intertextual y metatextual en su obra cardinal Rosinante to the Road Again, tal y como confiesa en su viaje a Toledo: «Toledo was still the Toledo of Cervantes' Novelas Ejemplares» (Dos Passos 2015: 37). En realidad, la literatura cervantina ya era su corpus literario de referencia antes de viajar a Espańa, pero ahora había constatado de primera mano cómo en Don Quijote se reflejaba, de alguna forma, el epítome del carácter español. Por todo ello, llegó a leer la novela más de nueve veces y al terminar la octava 
relectura en inglés ya se atrevió a leerla en español y a hacer un profundo estudio crítico, tal y como atestigua su biógrafo Townsend Ludington, quien cita las palabras del escritor sobre su experiencia lectora de esta novela y el profundo impacto que le produjo el paisaje de La Mancha:

Oh it's so wonderful and strange, the very place for the mad ardors, and pathetic beauty of the Knight of the Doleful Countenance -the red and the blue \& the grey- and the windmills perched like rabbits on all the hills and the gnarled olive trees climbing up the slopes (2003: 316).

\section{EL MITO LITERARIO QUIJOTESCO EN ROSINANTE TO THE ROAD AGAIN}

El fruto literario de esta primera etapa de inmersión absoluta en la cultura española se plasmó en Rosinante, que es un libro de viajes fragmentario o compendio de diecisiete capítulos donde el escritor describe su periplo cultural, literario, político, artístico y gastronómico con el claro empeño de descubrir lo que denominaba como el «gesto español» o la esencia cultural de nuestro país. En este sentido, hay que señalar que Dos Passos buscaba «in his depiction of a foreign culture to explore in striking new forms the meaning of his own» (Pizer 1997: 137), así como un país donde todavía no hubieran desaparecido los ideales míticos del pasado, «the full life of spirit in which the natural, the honest, and the good still existed» (Pizer 1997: 149). Y, sin duda, España ofrecía, en cuanto a ideales míticos, una gran plétora de narrativas históricas y artísticas fruto de la superposición de culturas a lo largo de su prolija historia.

Los ensayos de este libro de viajes que Dos Passos escribió entre 1920 y 1922 sobre nuestro país son, en muchos casos, una suerte de lienzos verbales de carácter pictórico donde plasma con descripciones sensoriales su visión holística de las tierras españolas, donde todavía se podía encontrar el espíritu heroico del pasado y había posibilidad de renovación. No cabe duda de que Rosinante es un compendio de imágenes visuales en las que el escritor demuestra, además, que era un pintor excelente, ya que en sus cuatrocientas obras pictóricas puso de manifiesto su dominio de técnicas tan diversas como la acuarela, el carboncillo, el óleo o el dibujo a lápiz. Así pues, en muchos de sus cuadros se dedicó a plasmar las experiencias sensoriales que captó durante sus viajes por nuestro país. En este punto hay que señalar que quizás en el carácter visual de su obra sobre España también pudo ejercer una fuerte influencia su profunda lectura y análisis de Don Quijote, ya que según el insigne cervantista Edward C. Riley:

Don Quijote es una novela concebida en términos fuertemente visuales, y cuestiones de percepción visual forman parte de la estructura y fábrica del libro. Es el caso también de la dualidad de perspectiva. Consecuencia de la peculiar locura de don Quijote es el hecho de que al lector se le recuerda repetidamente de una manera indirecta la apariencia física de cosas y personas del libro, incluso el caballero mismo. $\mathrm{Su}$ aberración óptica que le transforma todo -los molinos se vuelven gigantes, las 
ovejas guerreros, las ventas castillos- ejerce un efecto recíproco en el lector. Se le mete una comparación de las dos imágenes en la cabeza, por momentánea que sea (citado en Allen y Finch 2004: 13).

A pesar de que algunos críticos norteamericanos señalan que Rosinante no tiene las dimensiones literarias de Manhattan Transfer y de la trilogía de USA (Pizer 1997: 137), considero que es un testimonio literario de extraordinario valor para explorar e investigar el impacto de la cultura espańola en su obra modernista, la construcción de una utopía épica modernista basada en la mitología cervantina, la formación de la subjetividad del artista moderno, el proceso de internacionalización de la literatura modernista anglonorteamericana y, por último, el desarrollo del sujeto cosmopolita modernista a través del viaje y otros aspectos específicos que desarrollo en este trabajo. No obstante, sí hay algunos críticos que han sabido calibrar en su justa medida el valor de esta narración modernista; este es el caso de Donald Pizer, para quien se trata de un texto de gran interés, ya que «is a significant expression of what can be called the Modernistic expatriate imagination» (1997: 137).

Para entender el impacto que tuvo la literatura cervantina en Dos Passos hay que tener en cuenta los ensayos que escribió sobre literatura y el papel que tenían para el escritor la historia y los mitos culturales. En este sentido, es preciso señalar que el escritor muestra claramente en su obra literaria una relación dialéctica entre creatividad e historia. De hecho, Dos Passos puso de manifiesto durante su periodo más radical y experimental su vinculación utópica con los ideales anarquistas, su concepto de la totalidad de la historia y cómo su vinculación con el hecho histórico era inexorable en su literatura. En este sentido, hay que poner de manifiesto que el escritor concebía la literatura como un fenómeno artístico transcultural, tal y como se puede constatar en su lectura de los clásicos españoles y la incorporación y el análisis crítico de poetas tan señeros como Jorge Manrique, Joan Maragall, Juan Ramón Jiménez y Antonio Machado en Rosinante. Por otro lado, tras su constatación de que en la cultura norteamericana no podía encontrar una tradición mitológica poderosa y un pasado histórico dilatado, tuvo que viajar a Europa para investigar sobre los orígenes históricos de su cultura, puesto que esta cuestión era primordial para la internacionalización de su experiencia y creatividad, tal y como ya habían hecho otros escritores expatriados modernistas norteamericanos: Ezra Pound, T.S. Eliot, Gertrude Stein y Hemingway en Londres y París. Así pues, Dos Passos encontró en España su propia utopía modernista en Don Quijote, el sueño de escritores que, como él, huían del monetarismo, la industrialización y el voraz capitalismo norteamericano. Por lo tanto, en la península ibérica descubrió una historia milenaria que se perdía en los orígenes del hombre y una poderosa mitología centrada en su héroe paradigmático: don Quijote de La Mancha. La influencia de la obra cervantina en este libro de viajes muy poco convencional está presente en forma de intertextualidad temática, de caracterización y de alusión que subyace como un leitmotiv para construir una épica de viajes modernista.

Dos Passos era un hombre profundamente curioso, sus raíces portuguesas -era nieto de un zapatero que emigró de Ponta do Sol, en Madeira, a Nueva Yorkle hicieron sentir la necesidad de conocer sus orígenes ibéricos. Asimismo, se sentía 
profundamente atraído por el universo mitológico de la cultura europea y clásica. Para el escritor, la mítica pareja de don Quijote y Sancho Panza era el epítome de la Arcadia espańola que quizás todavía se podía recuperar, después de los horrores de la Primera Guerra Mundial que él había presenciado de forma directa con su experiencia en el frente de Francia. El idealismo de Dos Passos transformó las tierras españolas en paradigma de una civilización idílica y edénica, frente a los males de la nación norteamericana. Así pues, en Rosinante, Dos Passos pone a Madrid y La Mancha en el mapa de la modernidad junto a las metrópolis prototípicamente modernistas de Londres y París de los escritores expatriados en el viejo continente.

Por otro lado, hay que destacar que Dos Passos también forma parte de una larga tradición de escritores que de una forma u otra pusieron de manifiesto la impronta de la obra cervantina en las letras norteamericanas. Por citar los casos más relevantes hay que reconocer esta influencia intertextual en la obra de Washington Irving, William Dean Howells, Mark Twain, Herman Melville, William Faulkner, John Steinbeck, Jack Kerouac y Paul Auster. Por lo tanto, la recepción de Don Quijote en la literatura norteamericana es muy destacada y, como demuestra la crítica sobre este proteico diálogo literario transatlántico, la lectura comparatista e interdisciplinar que han hecho estos escritores en el contexto de la cultura norteamericana arroja luz desde la mirada distante, pero cercana de experiencias y planteamientos que nos ayudan a reinterpretar al escritor que imaginó a uno de los mitos más poderosos de la cultura universal.

En el caso específico de Dos Passos, la intertextualidad quijotesca es excepcional no solo por el profundo conocimiento que tenía el escritor norteamericano de la obra cervantina, tal y como queda plasmado en Rosinante, sino porque nos ofrece una versión modernista del Quijote transnacional, revisita el mito, lo transforma en un paradigma de la modernidad a través de su propia lectura y la de Miguel de Unamuno y lo presenta como una obra que no solo es el prototipo de lo español, sino que, en su opinión, es fuente de inspiración mítica para asumir la convulsa época de los años veinte. Asimismo, para el escritor en la obra cervantina se articula de forma diáfana el conflicto entre el idealismo y el pragmatismo y para él esta discusión ofrece soluciones a la crisis de valores en la que, a su juicio, se había sumido la sociedad norteamericana de su época.

Rosinante ha sido abordado desde la perspectiva de la literatura comparada en muy pocos estudios críticos. En este sentido, destacaría el estudio pionero en este campo de Catalina Montes (1980) y los estudios posteriores de Pizer (1997), Ludington (2003), Juncker (2010) y Marín Ruiz (2011). Sin embargo, el único que realmente se acerca de manera somera sin llegar a profundizar en los aspectos más complejos de la transmisión e intertextualidad del mito es el estudio de Catalina Montes. El resto de las aproximaciones reconocen la influencia o inciden de forma puntual en aspectos como el de la equivalencia de los personajes, pero no elaboran las conexiones del mito con la modernidad o las implicaciones de las lecturas interpuestas del mito. Por ello es muy importante focalizar el análisis en el hecho de que Dos Passos descubrió en Don Quijote de La Mancha el paradigma del idealismo frente a la industrialización, el monetarismo, el materialismo y el desplazamiento de las aspiraciones transcendentalistas y anarquistas que guiaban su existencia. Su 
pasión por la novela era tal que, mientras la leía y releía, escribía a sus amigos para que dejaran todo aquello que estuvieran haciendo y leyeran esta obra universal, a su juicio fundamental, para entender España y la condición humana en general. Asimismo, durante su viaje peripatético por España, Dos Passos siempre tuvo en mente la obra cervantina, era sin duda su mejor referente para entender nuestro país y para analizar tanto el pasado como el presente:

Downes and I decided it would be amusing to walk to Toledo. We set off down the arcaded Calle de Toledo and out the gate and along the white road. The road was merry with the jingling of huge twowheeled carts, each drawn by three or four or sometimes five hulking mules. Always in the lead was a little donkey trotting along with mincing steps. We talked with the arrieros. They gave us drinks out of their leather wine bottles. It wasn't today, we kept telling each other. This was el Quijote's and Sancho Panza's Spain (2015: 47).

En su intenso viaje por Castilla y La Mancha, Dos Passos busca incansablemente las figuras de don Quijote y Sancho Panza como una dualidad que, en sus palabras, simboliza la vieja y la nueva Espańa: la del pueblo llano que acepta la vida sencilla y la de los intelectuales que cuestionan la realidad. En esta búsqueda obstinada de la pareja cervantina, el escritor norteamericano no olvida el papel fundamental que tiene y le otorga a Rocinante en la construcción y desarrollo del mito, y al personaje animal dedicará escenas muy relevantes a lo largo de su viaje.

\section{ROCINANTE: SÍMBOLO DEL VIAJE INICIÁTICO}

La primera lectura de Rosinante conlleva necesariamente el análisis de las implicaciones que tiene el título para abundar en el viaje quijotesco de Dos Passos por España. Sin duda, estamos ante un libro de viajes inspirado en Don Quijote, el libro del viaje de la vida por antonomasia en cuanto a la forma episódica y al tema de la búsqueda del conocimiento o Bildungsreise a través de las aventuras caballerescas. Sin embargo, el escritor norteamericano le otorga un protagonismo sin par al personaje de Rocinante al titular la obra sobre su propio viaje con su nombre y al convertirlo en el centro temático y significativo de la obra. Tal vez Dos Passos rinde un homenaje al protagonista-animal más famoso de la literatura occidental, que ocupa el espacio narrativo más significativo de la épica cervantina junto a los protagonistas caninos de El coloquio de los perros (1613). No cabe duda de que cuando Dos Passos leyó la novela se sintió conmovido por la poderosa simbiosis del caballo con el caballero andante. Lo cierto es que en la extensa iconografía universal que existe sobre la novela, don Quijote y su rocín forman una única imagen muy poderosa a nivel visual. Es más, casi nadie se imagina al caballero en solitario sin su valioso caballo. En este sentido, hay que señalar que Dos Passos mostró una gran sensibilidad por la naturaleza y sus seres vivos y sentía un afecto muy especial por los animales. De hecho, asistió a alguna corrida de toros animado por su amigo Hemingway y la verdad es que el espectáculo no le agradó mucho. Al titular su obra más importante sobre España con el nombre de Rocinante reconoce la importancia 
significativa del caballo en la "epopeya cervantina» y le otorga un protagonismo temático esencial. Cabe constatar este aspecto en la sección IV, "Talk by the Road», en la que Telémaco y Lieo, los protagonistas del viaje, se encuentran con una pareja que claramente representa a don Quijote y Sancho Panza. El narrador visualiza en la distancia dos figuras: "Over the furrowed fields rode a man on a donkey and a man on a horse. It was a grey sway-backed horse that joggled in a little trot with much switching of a ragged tail» (2011: 34). En esta descripción inicial, el foco narrativo está en el caballo y en su aspecto canoso y descuidado. El jinete en cuestión se llama don Alonso y Telémaco se siente inevitablemente atraído por el caballo:

Then he walked over to the grey horse that stood with hanging head and drooping knees hitched to one of the acacias.

«I wonder what his name is». He stroked the horse's scrawny face.

«Is it Rosinante?»

The horse twitched his ears, straightened his back and legs and pulled back black lips to show yellow teeth.

"Of course it's Rosinante!"

The horse's sides heaved. He threw back his head and whinnied shrilly, exultantly (2011: 38).

En este momento final del capítulo Iv, la narración se cierra una vez más con el énfasis descriptivo en el caballo y se pone de manifiesto la centralidad temática que Dos Passos otorga a Rocinante, y cómo este se convierte en un símbolo del viaje iniciático en su obra: el viaje pausado, el recorrido paso a paso en un país que el escritor quiere conocer de forma profunda, a veces incluso a lomos de un rocín, experimentando las intensas vivencias del camino. En efecto, el escritor, tal y como comenta en el libro, recorrió muchas zonas de España en tren, a pie y también a caballo, explorando las tierras castellanomanchegas con auténtica devoción y con una intensidad difícil de describir.

No cabe duda de que Rocinante es personaje fundamental en Don Quijote, ya que es un espejo idealizado de los caballos fabulosos de los libros de caballería o de otros caballos eminentes de la historia que incluso se mencionan en la novela. Sin embargo, Rocinante es en realidad un rocín seco, enjuto y maltrecho por los largos años de servicio a su amo y este es el caballo que vuelve al camino en la versión de Dos Passos. No obstante, ambos Rocinantes adquieren la misma importancia que su amo: comparten el peso heroico y aventurero de sus dueños y experimentan una segunda oportunidad en su viaje a la búsqueda de aventuras. Del mismo modo, es un doble peculiar con el que don Quijote se complementa perfectamente porque tienen muchas cosas en común, aparte del físico enjuto, seco y desgarbado. No podía el hidalgo hacerse con otro caballo más joven, impetuoso e indomable porque no habría sido capaz de adaptarse a la vida procelosa de su amo. Por lo tanto, la elección es apropiada y se ajusta a las necesidades de Alonso Quijano, quien otorga al caballo un papel fundamental en su propia metamorfosis caballeresca, ya que emplea ocho días en buscar un nombre para sí mismo y cuatro días para buscarle un nombre apropiado a su rocín para que fuera un digno emblema de las aventuras que inician juntos. Según el narrador de Don Quijote, Rocinante «es el primero 
de todos los rocines del mundo» (28), «le pareció que ni Bucéfalo de Alejandro ni Babieca el del Cid con él se igualaban» (27). En este sentido, Marín Ruiz señala que «la comparación con caballos mitológicos [...] sirve para situar al rocín a la altura de la prestancia y valor de su amo, dotándole de una especial singularidad frente a otros animales que aparecen a lo largo de la novela» (2011: 340). Por tal motivo, «Rocinante adquiere una dimensión simbólica en el momento en que Cervantes lo convierte en portador de cualidades e ideales como la fidelidad, la conformidad y la libertad" (Marín Ruiz 2011: 341). En definitiva, considero que Dos Passos en Rosinante también le otorga al caballo un protagonismo simbólico y prominente al representar él por sí mismo no solo las virtudes que le otorga Cervantes, sino además la iniciativa de volver al camino, a la aventura de la vida y a la búsqueda de nuevos sueños utópicos de regeneración por tierras manchegas.

\section{EL VIAJE COMO DESARROLLO DE LA IDENTIDAD MODERNISTA COSMOPOLITA Y TRANSCULTURAL}

El narrador y protagonista de Rosinante, Telémaco, es el alter ego de Dos Passos y está acompañado por su ficelle Lieo ambos, a pesar de sus orígenes griegos, emulan claramente a la pareja quijotesca en una suerte de efecto especular. La analogía entre la pareja protagonista de Rosinante y la pareja protagonista de Don Quijote es más que llamativa y se sustenta en la intertextualidad y los paralelismos que, además, son establecidos por el narrador:

A- Telémaco-don Quijote: Telémaco, hijo de Odiseo y Penélope, es personaje clave de la Odisea de Homero y es el que combate desde la lejanía, como su propio nombre indica. Ambos personajes representan la vida del intelecto y el espíritu en Rosinante: «Don Quixote, the individualist who believed in the power of man's soul over all things, whose desire included the whole world in himself» (2011: 24).

B- Lieo-Sancho Panza: ambos tienen la función de personaje ficelle en los dos textos, ya que representan el contrapunto narrativo, ocupan el papel del confidente y los dos son los personajes que representan el mundo de los sentidos: «Sancho, the individualist, to whom all the world was food for his belly» (2011: 24).

A lo largo de su viaje iniciático por La Mancha la pareja protagonista de Rosinante llega a la villa toledana de Almorox y es en el capítulo III, titulado «The Baker of Almorox", donde Telémaco, el narrador de esta parte, profundiza y reflexiona sobre la historia y la cultura españolas en su indagación sobre el gesto y el carácter de sus individuos y las complejas raíces multiculturales que conforman la variopinta identidad nacional. En este sentido, la historia española es para Telémaco una inspiración muy poderosa debido a la complejidad de las culturas y pueblos que la constituyen: "Invasion after invasion, of Goths, of Moors, of Christian ideas, of the fads and convictions of the Renaissance» (2011: 44). La superposición de distintas culturas y pueblos de la Antigüedad sorprendió tanto a Dos Passos que incluso compartió 
con su amigo Rumsey Marvin la sensación de cómo los antiguos caminos tenían una suavidad aterciopelada por el efecto del paso de las distintas generaciones: «Do you know the wonderful feel of old roads which have been worn to a sort of velvet softness by the feet of generations and generations?» (citado en Rogers 2016: 86). Cabe constatar que, en gran medida, la pasión de Dos Passos por Don Quijote se basa precisamente en cómo, desde su perspectiva, la novela por antonomasia sintetiza de manera magistral la complejidad histórica y el carácter palimpséstico de la cultura espańola. Al fin y al cabo, en estos aspectos tan cruciales para el escritor radicaba la trascendencia de esta novela en la historia literaria española y universal.

Por otro lado, en el análisis del narrador sobre los habitantes de los pueblos manchegos, el panadero de Almorox se convierte en el paradigma real del ser humano honesto y bondadoso que vive en el mundo rural de una manera natural y armónica con el medio. Del mismo modo, el panadero de Almorox es, además, el protagonista de una realidad que para Telémaco-Dos Passos también se sustenta en el idealismo, la fantasía y la ensoñación en su viaje y percepción de España. Sin duda, estos son aspectos fundamentales en la construcción de su propia identidad modernista transcultural:

And predominant in the Iberian mind is the thought La vida es sueño: «Life is a dream». Only the individual, or that part of life which is in the firm grasp of the individual, is real. The supreme expression of this lies in the two great figures that typify Spain for all time: Don Quixote and Sancho Panza (2011: 24).

En su análisis de los personajes, el narrador va un paso más allá y descubre que la historia, la arquitectura y el arte españoles están marcados por esos aspectos que representa la pareja quijotesca de idealismo, espiritualidad, sensualidad y pragmatismo:

Through all Spanish history and art the threads of these two complementary characters can be traced, changing, combining, branching out, but ever in substance the same. Of this warp and woof have all the strange patterns of Spanish life been woven (2011: 25).

All that is greatest in their art, indeed, lies on the borderland of the extravagant, where sublime things skim the thin ice of absurdity. The great epic, Don Quixote, such plays as Calderón's La vida es sueño, such paintings as El Greco's Resurrección and Velázquez's dwarfs, such buildings as the Escorial and the Alhambra -all among the universal masterpieces- are far indeed from the middle term of reasonable beauty (2011: 27).

En «The Baker of Almorox», Dos Passos-Telémaco concluye con la siguiente reflexión:

Here was the gospel of Sancho Panza, I thought, the easy acceptance of life, the unashamed joy in food and color and the softness of women's hair. But as I walked out of the village across the harsh plain of Castile, grey-green and violet under the deepening night, the memory came to me of the knight of the sorrowful countenance, don Quixote, blunderingly trying to remould the world, pitifully sure of the power of his own ideal. And in these two Spain seemed to be manifest. Far indeed 
were they from the restless industrial world of joyless enforced labor and incessant goading war. And I wondered to what purpose it would be, should don Quixote again saddle Rosinante, and what the good baker of Almorox would say to his wife when he looked up from his kneading trough, holding out hands white with dough, to see the knight errant ride by on his lean steed upon a new quest (2011: 32-33).

La pasión que sentía Dos Passos por Don Quijote y la búsqueda incansable del espíritu y de la esencia más pura del quijotismo por las tierras de Castilla y La Mancha son trasunto de la necesidad de abundar en el mito literario, de encontrar y estudiar al prototipo, al hombre concreto en el que quizás se inspiró Cervantes para crear a aquel personaje excéntrico desde sus aspectos más idealistas y sublimes hasta lo puramente grotesco. El quijotismo y el gesto español atrajeron profundamente al escritor norteamericano que buscaba incansablemente la nobleza de espíritu, el sueño, la capacidad de búsqueda más allá de lo material y la posibilidad de reinventarse en cualquier momento de la vida. Su peregrinación por tierras españolas tiene ese sentido de búsqueda espiritual, de deseo profundo de llenar el vacío íntimo que le provocaba la deriva de la civilización norteamericana -el monetarismo, la industrialización, el materialismo exacerbado-. La duda y el cuestionamiento del progreso materialista de su país le llevaron directamente a los mitos clásicos de la literatura occidental, como don Quijote o Telémaco. Con este deseo quería habitar en una pancronía literaria, en un eterno retorno en el que actualizaba el pasado en el contexto de las vanguardias artísticas occidentales y por esa razón se inspiró en los clásicos españoles como gran fuente de conocimiento y tradición, tal y como hicieron los escritores T.S. Eliot o Federico García Lorca en su obra modernista.

\section{CONCLUSIONES}

Dos Passos encontró en Don Quijote de La Mancha la inspiración de un hombre joven que necesitaba reinventarse en medio de una profunda crisis espiritual, y que intentaba descubrir su auténtica pasión, su fantasía y su sueño ante la profunda insatisfacción que le producía la deriva materialista de su país y la crisis vital que experimentó con los horrores que conoció durante la Primera Guerra Mundial. Para ello se embarcó en un viaje de descubrimiento por los caminos de nuestro país, tal y como hizo su admirado héroe cervantino. En este sentido, se podría establecer un paralelismo con el personaje ficcional de Alonso Quijano, quien decide en medio de una crisis de madurez o senectud reinventarse y para ello se imagina pasiones y aventuras nuevas, tal y como también hizo su creador Miguel de Cervantes, un soldado fracasado que decidió, para no morir de melancolía y hastío, arriesgarlo todo con una novela que cambió la historia de la literatura universal. La base de la transformación que experimentan estos protagonistas de la vida y la ficción -Miguel de Cervantes, John Dos Passos, Alonso Quijano, Telémaco y don Quijote- es la creencia ciega en el sueño y en el viaje como motor de cambio y transformación humana. No cabe duda de que John Dos Passos encontró en Don Quijote de La Mancha y en las tierras españolas la inspiración para fraguar su sueño y su propia 
utopía modernista, que le dio la oportunidad de reinventarse y seguir con su gran pasión por la historia y la literatura. En suma, su viaje por España lo marcó tan profundamente que le aportó una nueva visión utópica de la modernidad literaria.

Recibido: junio de 2018; ACEPTADo: octubre de 2018. 


\section{BIBLIOGRAFÍA}

Allen, John J. y Patricia S. Finch (2004): Don Quijote en el arte y pensamiento de occidente, Madrid: Cátedra.

Cervantes Saavedra, Miguel de (1999): Don Quijote de la Mancha, edición de Martín Alonso, Madrid: EDAF.

Dos Passos, John (2003): «A Pushcart at the Curb», en Travel Books and Other Writings, Washington: Library of America.

Dos Passos, John (2011) [1922]: Rosinante to the Road Again, London: Onesuch Press.

Dos Passos, John (2015) [1966]: The Best Times: An Informal Memoir, London: Open Road.

Juncker, Clara (2010): «John Dos Passos in Spain», Miscelánea: A Journal of English and American Studies 42: 91-103.

Ludington, Townsend (1998): John Dos Passos. A Twentieth Century Odissey, New York: Carroll \& Graf Publishers.

Ludington, Townsend (2003): «I Am So Fascinated by Spain’: John Dos Passos, January 1917», en Carme Manuel \& Paul S. Derrick (eds.), Nor Shall Diamond Die: American Studies in Honour of Javier Coy, Valencia: Biblioteca Javier Coy-Universitat de Valencia, 303-319.

Marín Ruiz, Ricardo (2011): «Tras los pasos de Rocinante: imitación y re-elaboración del personaje cervantino en John Dos Passos, Graham Greene y John Steinbeck», en Hans Christian Hagedorn (ed.), Don Quijote en su periplo universal: aspectos de la recepción internacional de la novela cervantina, Cuenca: Universidad de Castilla-La Mancha, 337-362.

Montes, Catalina (1980): La visión de España en la obra de John Dos Passos, Salamanca: Almar.

Piñero Gil, Eulalia (2018): «Introducción», en Invierno en Castilla y otros poemas de John Dos Passos, Sevilla: Editorial Renacimiento, 7-71.

Pizer, Donald (1997): «John Dos Passos's Rosinante to the Road Again and the Modernist Expatriate Imagination", Journal of Modern Literature 21 (1): 137-150.

Rogers, Gayle (2016): «Restaging the Disaster: Dos Passos, Empire, and Literature After the SpanishAmerican War", en Gayle Rogers, Incomparable Empires. Modernism and the Translation of Spanish and American Literature, New York: Columbia University Press, 76-106.

Sáenz de la Calzada, Margarita (2011): La Residencia de Estudiantes. Los residentes, Madrid: CSIC; Acción Cultural Española; Residencia de Estudiantes. 
